This item was submitted to Loughborough's Research Repository by the author.

Items in Figshare are protected by copyright, with all rights reserved, unless otherwise indicated.

\title{
Teaching our children when to eat: how parental feeding practices inform the development of emotional eating. A longitudinal experimental design
}

PLEASE CITE THE PUBLISHED VERSION

http://ajcn.nutrition.org/content/101/5/908.abstract

\section{PUBLISHER}

(C) American Society for Nutrition

\section{VERSION}

AM (Accepted Manuscript)

\section{PUBLISHER STATEMENT}

This is a free access article, distributed under terms (http://www.nutrition.org/publications/guidelines-andpolicies/license/) that permit unrestricted noncommercial use, distribution, and reproduction in any medium, provided the original work is properly cited.

\section{LICENCE}

\section{All Rights Reserved}

\section{REPOSITORY RECORD}

Farrow, Claire V., Emma Haycraft, and Jacqueline Blissett. 2015. "Teaching Our Children When to Eat: How Parental Feeding Practices Inform the Development of Emotional Eating. A Longitudinal Experimental Design". Loughborough University. https://hdl.handle.net/2134/16912. 
Published in the American Journal of Clinical Nutrition, 2015

\section{Teaching our children when to eat: how parental feeding practices inform the development of emotional eating. A longitudinal experimental design.}

\section{Claire V Farrow, Emma Haycraft \& Jackie M Blissett}

School of Life and Health Sciences, Aston University (CVF); School of Sport, Exercise \& Health Sciences, Loughborough University (EH); School of Psychology, The University of Birmingham (JMB)

All correspondence or requests for reprints should be addressed to Dr Claire Farrow, School of Psychology, Life and Health Sciences, Aston University, Aston Triangle, Birmingham. B4 7ET. UK.c.farrow@aston.ac.uk Tel: 01212045384 Fax: 01212044090

Abbreviations: BMI: Body Mass Index; SD: Standard Deviation; SDS: Standard Deviation Score; Kcl: Kilocalories

Running head: The development of emotional eating Names for PubMed indexing: Farrow, Haycraft, Blissett Registered as a trial at clinicaltrials.gov as NCT01122290. This research was not externally funded. 


\section{Abstract}

2

Background: Emotional eating in children has been related to the consumption of

high energy dense foods and obesity, but the development of emotional eating in young

children is poorly understood. Objective: The objective was to evaluate whether emotional eating can be induced in 5-7 year old children in the laboratory and to assess whether parental use of overly controlling feeding practices at 3-5 years predicts a greater subsequent tendency for children to eat under conditions of mild stress at ages 5-7. Design: Forty-one parent-child dyads were recruited to participate in this longitudinal study which involved parents and children being observed consuming a standard lunch, completing questionnaire measures of parental feeding practices, participating in a research procedure to induce child emotion (or a control procedure) and observing child consumption of snack foods. Results: Children at ages 5-7 exposed to a mild emotional stressor consumed significantly more calories from snack foods in the absence of hunger compared to children in a control group. Parents who reported using more food as a reward and restriction of food for health reasons with their children at ages 3-5 were more likely to have children who ate more under conditions of negative emotion at ages 5-7. Conclusion: Parents who overly control children's food intake may unintentionally teach children to rely on palatable foods to cope with negative emotions. Further research is needed to evaluate the implications of these findings for child food intake and weight outside of the laboratory setting.

Keywords: child emotional eating, child feeding, snack food, obesity, longitudinal 


\section{Introduction}

Emotional eating can be defined as "eating in response to a range of negative emotions such as anxiety, depression, anger and loneliness to cope with negative affect” (1). In adults and adolescents emotional eating has been linked to heavier weight, obesity, and greater consumption of high energy-dense sweet and salty foods (2, 3, 4 although see 5 for conflicting results). In younger children, around one quarter of parents of 5 year olds report that their children exhibit emotional disinhibition with food (6) and 63\% of children aged 513 report eating in response to mood (7). Parents of 2-6 year olds tend to report great emotional under-eating rather than over-eating (8).Van Strien and Oosterveld (9) suggest that young children lose their appetite as a natural response to stress associated with a loss of gut activity (10). Emotional overeating may be a learned abnormality, likely to exacerbate ill health. Given that eating behaviours track across life, understanding the development of this behaviour is critical $(11,12)$.

Parental feeding practices have been shown to impact upon children’s developing eating behaviours $(13,14,15)$. Previous research suggests that parental use of food as an emotional tool may teach children to use food to alleviate or distract from negative emotion (see 16, 17). Other feeding practices which overly control children's food intake have also been shown to predict unhealthy eating behaviours as they are believed to undermine children's ability to regulate their hunger and satiety. Parental use of food as a reward or for emotional reasons has been correlated with emotional undereating in 3-6 year old children (13), and pressuring children to eat has been shown to predict greater emotional eating in 5 and 7-12 year olds respectively $(6,18)$. However, most of this research is cross-sectional and utilises parent report of feeding practices and eating behaviours $(13,15)$, making it difficult to establish causality. 
Previously Blissett et al. (16) developed a novel procedure for inducing child emotion

in a laboratory setting, however their original sample was reduced significantly because many

3-5 year olds failed to respond to the emotion manipulation. The first aim of this study is to refine this emotional manipulation to assess its efficacy in a sample of 5-7 year olds, who may be more capable of accurately rating their mood. The second aim is to assess whether children aged 5-7 are more prone to eat in the absence of hunger when under conditions of mild stress in comparison to a control group. The final aim is to ascertain whether parents who report using high levels of controlling feeding practices with their 3-5 year old children have children who are more likely to emotionally overeat when they experience stress in a laboratory setting 2 years later.

\section{Subjects and Methods}

\section{$\underline{\text { Participants }}$}

A small sample of 41 parent-child dyads participated in this longitudinal study which was part of a larger study described elsewhere (16). Participants were recruited to this study via advertisements to parents in the East-Midlands area of the UK. Families were eligible to participate if they had a child aged between 2 and 5 years old with no medical conditions affecting eating or feeding. Families were followed up two years later (time point 2). Following data screening, we removed six families from the original dataset for a variety of reasons (see data analysis section). This left a final sample of 35 children; 16 boys and 19 girls. The children's ages ranged from 34 to 59 months at time point 1 (mean $=46$ months, $\mathrm{SD}=7.18)$. Mean child age at Time point 2 was 6.15 years $(\mathrm{SD}=0.56$, range $5-7$ years $)$. Most (91\%) of the sample described their ethnicity as White British. This study was approved by the ethics committee at Loughborough University and registered as a trial at 
clinicaltrials.gov as NCT01122290. All procedures were conducted in accordance with the Declaration of Helsinki as revised in 1983.

\section{Procedure}

Time point 1: At time point 1, families were welcomed to the laboratory and mothers completed a battery of self-report questionnaires. These included a demographics questionnaire and the following subscales from the Comprehensive Feeding Practices Questionnaire (CFPQ: 19): use of food as a reward, use of food for emotion regulation, restriction for weight, restriction for health, and pressure to eat. Questions are answered using a Likert scale ranging from 1 (never/ disagree) to 5 (always/ agree) with higher scores indicating greater use of the particular feeding practice. Full details of the other measures completed at time point 1 , not used within this paper, and the baseline procedure are described elsewhere (16).

Time point 2: At time point 2, children were welcomed to the laboratory with their mothers and were given an opportunity to familiarise themselves with the room and play with the age-appropriate toys available within the laboratory. All mother-child dyads were given a standardised lunch. The child's lunch consisted of: 1 white bread roll, 1 slice of chicken, 1 slice of cheese, 4 cheese crackers, 3 pieces of chopped apple, 5 carrot sticks and 2 chocolate chip cookies. Mothers’ lunches were the same but slightly larger as they included 2 bread rolls, 2 slices of chicken and 2 slices of cheese. Where mothers indicated that they or their child was vegetarian, chicken was not offered and was replaced with additional cheese.

Mothers and children were each provided with a drink of water with their meal. Mothers and children were asked to eat from their own plates until they felt full and could ask for additional food if they wished (no families requested more food). Once they had finished eating, mothers and children each took part in separate procedures within the same room. Mothers were asked to complete a series of questionnaires whilst the child engaged in a task 
with the researcher. Children were randomly allocated to either the experimental mood manipulation group, or to the control group, with children being in the same group that they had been involved in at time point 1 . Children could not see their mothers but mothers could watch their child through a screen if they wanted to. After the procedures had finished all mothers and children were weighed and measured in light indoor clothes without shoes. Weight and height scores were converted to BMI scores for mothers and to age and genderadjusted BMI SDS scores for children (20).

Experimental group: Children were shown a 5 point smiley-face rating scale to measure their baseline mood according to pictures. Responses are coded on a 5 point likert scale where 5 = very happy, $3=$ neutral and 1 = very sad; this method has previously been shown to discriminate mood in children in this age range $(16,21)$. Children were then shown a selection of small toys and invited to choose one which they were told they would receive on completion of a colouring task. The toy was placed in sight, but out of reach. Children then took part in an age appropriate mood induction task where they were asked to colour in a drawing. Sections of the drawing were numbered and a set colour was assigned to each number (e.g., red for all the sections marked with a "1"). The colour key was visible to the children and the researcher went through this with them such that the child knew which colour crayon was to be used in each area prior to beginning colouring. The children coloured in the drawing, but when they got to the final number, number 6 , they realised that the required purple crayon was missing. The researcher then told the child that, because they hadn't completed the colouring, they couldn't have their chosen toy. The experimenter presented the child with the smiley-face rating scale and asked them to indicate their mood now that they couldn't have their toy. The researcher then stated that she would look for the missing crayon and placed six bowls of snack foods in front of the child, which had each been pre-weighed and were presented in separate bowls. Manufacturer nutritional labels were 
used to calculate kilocalories for each snack food, these included: 6g salted crisps (approx. 32kcal), 2 chocolate chip cookies (approx. $115 \mathrm{kcal}$ ), 21 chocolate buttons (approx. $115 \mathrm{kcal}$ ), 3 small breadsticks (approx. 31 kcal), 2 carrot sticks (approx. 6kcal), and 9 green grapes (approx. 32 kcal). The child was told that they could eat any of the snacks, or play with nearby toys, while the researcher looked around for the crayon. After 4 minutes, the researcher 'found' the missing crayon and handed it to the child. The child then completed the colouring task, received their chosen toy and re-rated their mood using the smiley face scale, as a check that all children's mood had returned to pre-manipulation standard or above (in all cases mood was returned to baseline or happier mood).

Control group: The procedure was identical for children in the control group except that there was no missing crayon for these children and they received their chosen toy after completing the colouring task. Children in the control group rated their mood before and after the colouring task and were given the option to help themselves to the same range of snack foods (as above), or to play with the toys in the laboratory, whilst the experimenter "tidied up”. As above, the bowls of snack food were removed after 4 minutes and re-weighed.

\section{Data analysis}

Six parent-child dyads were removed from the data set for the following reasons:

child showed an incongruous mood shift (e.g., mood did not deteriorate in the experimental condition or mood deteriorated in the control group), child attended with a grandparent, or child was deemed to be an outlier according to their BMI SDS score, leaving a final sample of 35. Independent sample t-tests were used to examine whether there were any differences between the control and experimental groups according to child age, maternal education, child BMI SDS score, maternal BMI or parental reported feeding practices. Pearson's correlations were used to explore whether these demographic variables were related to children's snack food consumption data at Time point 2. Independent sample t-tests were 
used to explore whether there were gender differences for children on parental reports of feeding practices or child consumption data.

For the first aim, to explore the efficacy of the emotion manipulation at inducing negative emotion, paired t-tests were used to examine whether experimental group children reported significant differences in their mood before and after the emotion induction procedure. Independent sample t-tests were used to examine whether the experimental group children differed in mood from control group children. For the second aim, to assess whether children ate more under conditions of stress, we used ANCOVA. ANCOVA was also used to explore whether parental feeding practices at time point 1 (high or low scores on feeding practices) predicted greater consumption of snack foods at time point 2. For each ANCOVA there were 2 fixed factors: group (experimental or control) and feeding practice measured at T1 (high or low according to the group mean for each feeding practice), with maternal BMI and child BMI SDS score as covariates. The dependent variable was total kilocalories consumed from all of the snack foods in the absence of hunger.

\section{Results}

\section{$\underline{\text { Screening for confounding variables }}$}

Independent sample t-tests indicated that there were no significant differences between children in the control or experimental group according to maternal education, maternal BMI, child age, or parentally reported child feeding practices at time-point 1 (see Table 1).

However there were significant differences between the control and experimental group children according to child BMI SDS score (see Table 1). Two-tailed Pearson's correlations were run to ascertain whether maternal education, maternal BMI, child age or child BMI SDS were related to child consumption of different foods. There were no significant relationships with the exception of maternal BMI which was significantly correlated with child 
consumption of calories from cookies at time point $2(\mathrm{r}=0.46, \mathrm{p}<0.05)$. Therefore in all subsequent analyses the effects of child BMI SDS and maternal BMI were controlled for. Independent sample t-tests indicated that there were no significant differences between girls and boys according to parent reports of feeding practices or child consumption data, therefore child gender was not controlled for in the analyses.

\section{Differences between control and experimental group}

Paired sample t-tests suggested that the emotion induction procedure had been successful at altering child emotion with significant differences between child mood before and after the emotion induction in the experimental group. In comparison, in the control group children there was no significant difference in their mood ratings before and after completing the task (see Table 2). Moreover, independent sample t-tests indicated that there were significant differences in child reported mood after the mood induction/control task when comparing mood for children in the experimental group after the mood induction to baseline mood for children in the control group: $\mathrm{t}(26)=-10.27, \mathrm{p}<0.001$. Importantly the experimental group's mood ratings returned to baseline after completing the procedure (see Table 2). There was a significant difference in terms of kilocalories consumed from the snack foods between children in the experimental group and those in the control group (see Table 1).

\section{$\underline{\text { ANCOVAs }}$}

There were no significant main effects or interaction effects in the ANCOVAs using parental use of food for emotion regulation, pressure to eat or restriction of food for weight reasons, with the exception of the effect of test group which significantly predicted child snack food intake as described below.

Food as a reward: In an ANCOVA exploring differences in energy intake according to parental use of food as a reward at T1 (high or low) and group (experimental or control), 
controlling for the covariates of child BMI SDS score and maternal BMI, the effect of test group was significant $(F(1,29)=10.36, \mathrm{p}<0.05)$ with children in the experimental group consuming significantly more calories compared to those in the control group. The range of total kilocalories consumed during the 4 minute testing period ranged from 0 to 141.73 in the control group and from 0 to 512.15 in the experimental group (see Table 1). There was no significant main effect for use of food as a reward but there was a significant interaction between group and use of food as a reward in predicting calorie intake $(F(1,29)=6.01$, $\mathrm{p}<$ 0.05). Children in the control group ate fewer calories when exposed to high use of food as a reward $(\mathrm{N}=8)$ compared to those exposed to low use of food as a reward $(\mathrm{N}=10)$. In contrast, children in the experimental group ate more calories when exposed to high use of food as a reward $(\mathrm{N}=5)$ compared to low use of food as a reward $(\mathrm{N}=12)$ (See Figure 1).

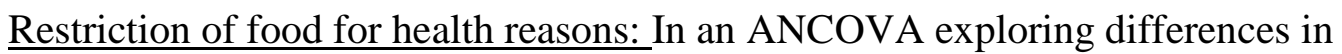
energy intake according to parental use of restriction for health reasons at T1 (high or low) and group (experimental or control), controlling for the covariates of child BMI SDS score and maternal BMI, there was again a significant effect of test group and also a significant interaction between experimental group and maternal use of restriction for health reasons $(F(1,29)=5.48, p<0.05)$. When decomposed further the results indicated that children in the control group who were exposed to high levels of restriction for health reasons $(\mathrm{N}=8)$ ate fewer calories than those exposed to low restriction $(\mathrm{N}=10)$, whereas children exposed to high levels of restriction for health reasons who were also exposed to stress $(\mathrm{N}=8)$ ate more total calories than those exposed to low restriction $(\mathrm{N}=9)$ (See Figure 2).

\section{Discussion}

This study aimed to assess the efficacy of a refined age-appropriate emotion manipulation in order to establish whether emotional eating can be observed in a group of 5-7 
year old children. It further aimed to evaluate whether parents who report using more controlling feeding practices with their 3-5 year old children are subsequently more likely to find that their children are prone to emotionally overeat 2 years later. The findings of this small scale study indicate that 5-7 year old children exposed to an emotion induction procedure consumed significantly more calories compared to children in a control group. Moreover greater maternal use of food as a reward and restriction of food for health reasons at age 3-5 was associated with greater child food intake in the absence of hunger 2 years subsequently.

In our previously published work with these children at ages 3-5 (16), there were no meaningful differences between children in the experimental or control groups in terms of the kilocalories that they consumed, suggesting that emotional overeating is not a common response in children as young as 3-5. However when observing these children 2 years subsequently, we found a significant effect of the emotion manipulation on snack food intake in the absence of hunger. At ages 5-7, children in the experimental group ate more calories in the 4 minute testing window compared to children in the control group. The range of total kilocalories consumed in this 4 minute period was 0 - 512kcl in the experimental group, compared to $0-141 \mathrm{kcl}$ in the control group. Although this difference is striking, the real life implications of this are potentially more profound given that children may face a number of emotional stressors during their everyday lives and, as they age, they are likely to have longer periods to freely access food. Previously it has been suggested that emotional overeating is a learned and abnormal response to stress in young children, and stress should naturally inhibit the tendency to eat (10). These findings support this suggestion and it may be that at some point between the ages of 4 and 6 the tendency, and perhaps opportunity, to emotionally overeat increases in many children. Our findings suggest that one factor which may contribute to this tendency is the feeding practices that young children are exposed to. 
The findings indicate that, compared to a control group, under conditions of negative emotion children were significantly more likely to consume food at ages 5-7 if their parents had reported greater use of food as a reward or use of restriction of food for health reasons 2 years previously. Overly controlling feeding practices such as these are likely to be associated with presenting and forbidding foods in situations which override children's natural signals of hunger and satiety. It may be that these more controlling feeding practices which restrict and reward children with food are teaching children to see palatable foods as a tool which can be used to alleviate distress (16). By exploring these relationships longitudinally over time, we have attempted to tease apart causality in these relationships, but it is of course possible that parents utilise these more controlling feeding practices with children who are already highly responsive to the rewarding properties of food, or have a tendency to overeat $(22,23,24)$.

Children's eating behaviour is highly complex and multifaceted and it is likely that several other factors, not least a parent's own tendency to emotionally eat, also impact upon the child's tendency to eat in the context of negative emotion $(25,26)$. Contrary to our hypotheses, there was no effect over time of parental pressure to eat, use of food for emotion regulation, or restriction of food for weight reasons on child subsequent emotional eating. Previous research has found that pressure to eat is associated with fussier eating and lower child consumption of pressured foods (which are often healthy foods such as fruits and vegetables) (27). Although the use of pressure may not be conducive to encouraging greater subsequent intake of pressured foods, it may be that pressure to eat has no particular detrimental effect on the tendency to overeat in the context of stress, given that the foods chosen in such contexts are not often those associated with pressuring feeding practices. The findings regarding use of food for emotion regulation are more puzzling, and of all of the feeding practices assessed, we would have expected that higher use of food to regulate child emotion should have been linked with greater subsequent food intake in the 
context of a mild stressor. It is possible that the effects of the use of food for emotion regulation may become more powerful predictors of emotional eating behaviour with increasing child age and future research is needed with larger samples to fully explore these relationships.

The findings of this research are novel and unique and to our knowledge this is the first study to explore the impact of parental feeding practices over time upon experimentally observed emotional eating in young children. However it is important to stress that these findings are limited to a very small sample. The longitudinal and lab based nature of this study meant that the sample size was limited and it is essential that these findings are replicated in larger samples with greater statistical power. Such replication should seek to recruit families from more diverse social and ethnic backgrounds in order to allow for generalisation to more varied participant groups, and also to increase our understanding of how ethnic and social factors and broader indices of family food environments may impact upon these relationships. In comparison to our previously published work, the emotion manipulation procedure was much more successful at altering child mood; this may be an effect of the specific emotion manipulation procedure used or a consequence of the sample of older children understanding the methods and measures more clearly. Further novel developments are required to allow for the study of emotional eating in young children, but these must strike a careful balance between the efficacy of such methods and the ethics of altering child mood to measurable degrees. Further research is also required to explore how parental feeding practices may impact upon child food consumption in the context of a wider variety of different emotional experiences. For example, Tanofsky-Kraff et al. (28) report that eating in response to being happy (followed by boredom) is the most commonly endorsed reason for emotional eating in older children and adolescents, and these more varied emotions warrant exploration. 
The findings of this research indicate that emotional eating can be observed in children as young as 5-7, and that previous exposure to more controlling parental feeding practices can exacerbate the tendency to emotionally overeat in children of this age. Given that emotional overeating tends to increase as children age (12), research is needed to understand the

303 implications of this research in the context of everyday life where children have free access to 304 food in order to inform the development of tailored prevention and intervention guidelines for 305 families.

\section{Acknowledgements}

With thanks to Laura Houldcroft, Faye Powell, Hannah White, Radhika Kotak, Laura

309 Richards, Adele Phillips, Priti Modhwadia and Jodie Hallett for their help with data

310 collection and coding. CVF, EH and JMB contributed to the design of the study and the write

311 up. CVF and EH oversaw the data collection, CVF analyzed the data and had primary

312 responsibility for the final content. The authors have no conflict of interest to declare. 


\section{References}

1. Faith MS, Allison DB, Geliebter A. (1997). Emotional eating and obesity: Theorectical considerations and practical recommendations. In: Dalton S, ed. Obesity and Weight Control: The Health Professional's Guide to Understanding and Treatment. Gaithersburg, MD: Aspen, 1997: 439-465.

2. Baños RM, Cebolla A, Moragrega I, Van Strien T, Fernández-Aranda F, Agüera Z, de la Torre R, Casanueva FF, Fernández-Real JM, Fernández-García JC, et al. Relationship between eating styles and temperament in an Anorexia Nervosa, Healthy Control, and Morbid Obesity female sample Appetite 2014; 76: 76-83. doi: 10.1016/j.appet.2014.01.012.

3. Braet C, Van Strien T. Assessment of emotional, externally induced and restrained eating behaviour in nine to twelve-year-old obese and non-obese children. Behav Res Ther 1997; 35: 863-873.

4. Nguyen-Michel ST, Unger JB, Spruijt-Metz D. Dietary correlates of emotional eating in adolescence. Appetite 2007; 49: 494-9.

5. Caccialanza R, Nicholls D, Cena H, Maccarini L, Rezzani C, Antonioli L, Dieli S, Roggi C. Validation of the Dutch eating behaviour questionnaire parent version (DEBQ-P) in the Italian population: A screening tool to detect differences in eating behaviour among obese, overweight and normal-weight preadolescents. Eur J Clin Nutr 2004; 58: 1217-1222.

6. Carper JL, Orlet Fisher J, Birch LL. Young girls' emerging dietary restraint and disinhibition are related to parental control in child feeding. Appetite 2000; 35: 121-9. 7. Shapiro JR, Woolson SL, Hamer RM, Kalarchian MA, Marcus MD, Bulik CM. Evaluating binge-eating disorder in children: Development of the children's binge eating disorder scale (C-BEDS). Int J Eat Disord 2007; 40: 82-89.

8. Wardle J, Guthrie CA, Sanderson S, Rapoport L. Development of the Children's Eating Behaviour Questionnaire. J Child Psychol Psychiatry 2001; 42: 963-70. 
9. van Strien T, Oosterveld P. The children's DEBQ for assessment of restrained, emotional, and external eating in 7- to 12-year-old children. Int J Eat Disord 2008; 41: 72-81. 10. van Strien T, Ouwens MA. Effects of distress, alexithymia and impulsivity on eating. Eat Behav 2007; 8: 251-7.

11. Farrow, C \& Blissett, J. Stability and continuity of parentally reported feeding practices and child eating behaviours from 2-5 years of age. Appetite 2012; 58: 151-156.

12. Ashcroft J, Semmler C, Carnell S, van Jaarsveld CH, Wardle J. Continuity and stability of eating behaviour traits in children. Eur J Clin Nutr 2008; 62: 985-90.

13. Powell F, Farrow C, Meyer C. Food avoidance in children: the influence of maternal feeding practices and behaviours. Appetite 2011; 57: 683-692

14. Mitchell G, Farrow C, Haycraft E. Parental influences on children's eating behaviour and characteristics of successful parent-focussed interventions. Appetite 2013; 60: 85-94.

15. Webber L, Cooke L, Hill C, Wardle J. Associations between children's appetitive traits and maternal feeding practices. J Am Diet Assoc 2010; 110: 1718-22. doi: 10.1016/j.jada.2010.08.007.

16. Blissett J, Haycraft E, \& Farrow C. Inducing preschool children's emotional eating: relations with parental feeding practices. Am J Clin Nutr 2010; 92: 359-65. doi: 10.3945/ajcn.2010.29375.

17. Braden A, Rhee K, Peterson CB, Rydell SA, Zucker N, Boutelle K. Associations between child emotional eating and general parenting style, feeding practices, and parent psychopathology. Appetite 2014; 80: 35-40. doi: 10.1016/j.appet.2014.04.017.

18. van Strien T, Bazelier FG. Perceived parental control of food intake is related to external, restrained and emotional eating in 7-12-year-old boys and girls. Appetite 2007; 49: 618-25. 
19. Musher-Eizenman D, Holub S. Comprehensive Feeding Practices Questionnaire: Validation of a New Measure of Parental Feeding Practices. J. Pediatr. Psychol 2007; 32: 960-972. doi:10.1093/jpepsy/jsm037

20. McCarthy HD, Cole TJ, Fry T, Jebb SA, Prentice AM. Body fat reference curves for children. Int J Obes (Lond) 2006; 30: 598-602.

21. Weisberg DP, Beck SR. Children's thinking about their own and others' regret and relief. J Exp Child Psychol 2010; 106: 184-91. doi: 10.1016/j.jecp.2010.02.005.

22. Rhee K, Coleman S, Appugliese DP, Kaciroti NA, Corwyn RF, Davidson NS, Bradley RH, Lumeng JC. Maternal Feeding Practices Become More Controlling After and Not Before Excessive Rates of Weight Gain. Obesity 2009; 19: 1724-1729.

23. Farrow C, Galloway A, Fraser K. Within-family differences in sibling's eating behaviours and parental reports of child feeding practices. Appetite 2009; 52: 307-312.

24. Haycraft E, Blissett J. Predictors of paternal and maternal controlling feeding practices with 2 to 5-year-old children. Journal of Nutrition Education and Behavior 2012; 44: 390397. DOI: 10.1016/j.jneb.2010.03.001

25. Jahnke DL, Warschburger PA. Familial Transmission of Eating Behaviors in Preschoolaged Children. Obesity 2012; 16: 1821-1825. doi: 10.1038/oby.2008.255

26. Whitaker RC, Wright J, Pepe MS, Seidel KD, Dietz WH. Predicting Obesity in Young Adulthood from Childhood and Parental Obesity. N Engl J Med 1997; 337: 869-873 27. Galloway, AT, Fiorito LM, Francis LA, Birch LL. 'Finish your soup’: Counterproductive effects of pressuring children to eat on intake and affect. Appetite 2006; 46: 318-323 28. Tanofsky-Kraff M, Theim KR, Yanovski SZ, Bassett AM, Burns NP, Ranzenhofer LM, Glasofer DR, Yanovski JA. Validation of the emotional eating scale adapted for use in children and adolescents (EES-C). Int J Eat Disord 2007; 40: 232-40. 
Table 1: Descriptive statistics for sample characteristics, feeding practices and child food intake between control and experimental group children

\begin{tabular}{|c|c|c|c|}
\hline & $\begin{array}{l}\text { Control group } \\
\mathrm{N}=18\end{array}$ & $\begin{array}{l}\text { Experimental group } \\
\mathrm{N}=17\end{array}$ & $\mathrm{p}$ value \\
\hline $\begin{array}{l}\text { Maternal years post- } \\
16 \text { education }^{2}\end{array}$ & $4.03 \pm 3.33$ & $4.94 \pm 2.22$ & 0.35 \\
\hline Maternal BMI $^{2}$ & $25.21 \pm 4.91$ & $25.03 \pm 4.97$ & 0.92 \\
\hline Child age, months ${ }^{2}$ & $74.20 \pm 5.69$ & $74.15 \pm 7.01$ & 0.054 \\
\hline Child BMI SDS score $^{2}$ & $-0.45 \pm 0.67$ & $0.32 \pm 0.74$ & 0.003 \\
\hline $\begin{array}{l}\text { Use of food as a } \\
\text { reward }^{1}\end{array}$ & $2.39 \pm 1.10$ & $2.41 \pm 1.14$ & 0.97 \\
\hline $\begin{array}{l}\text { Use of food for } \\
\text { emotion regulation }^{1}\end{array}$ & $1.92 \pm 0.62$ & $1.92 \pm 0.69$ & 0.98 \\
\hline Restriction for weight $^{1}$ & $1.81 \pm 0.52$ & $1.80 \pm 0.54$ & 0.97 \\
\hline Restriction for health $^{1}$ & $3.27 \pm 0.70$ & $3.15 \pm 1.13$ & 0.67 \\
\hline Pressure to eat $^{1}$ & $3.17 \pm 1.02$ & $2.62 \pm 0.84$ & 0.10 \\
\hline $\begin{array}{l}\text { Kilocalories } \\
\text { consumed from foods }{ }^{2}\end{array}$ & $30.17 \pm 48.97$ & $109.27 \pm 123.70$ & 0.02 \\
\hline
\end{tabular}

Mean \pm SD scores are reported. Independent sample t-tests were used to compare the two groups. ${ }^{1}$ Measure taken at time point $1 ;{ }^{2}$ measure taken at time point 2. 
Table 2: Comparisons of child mood within and between groups at different time points across the procedure.

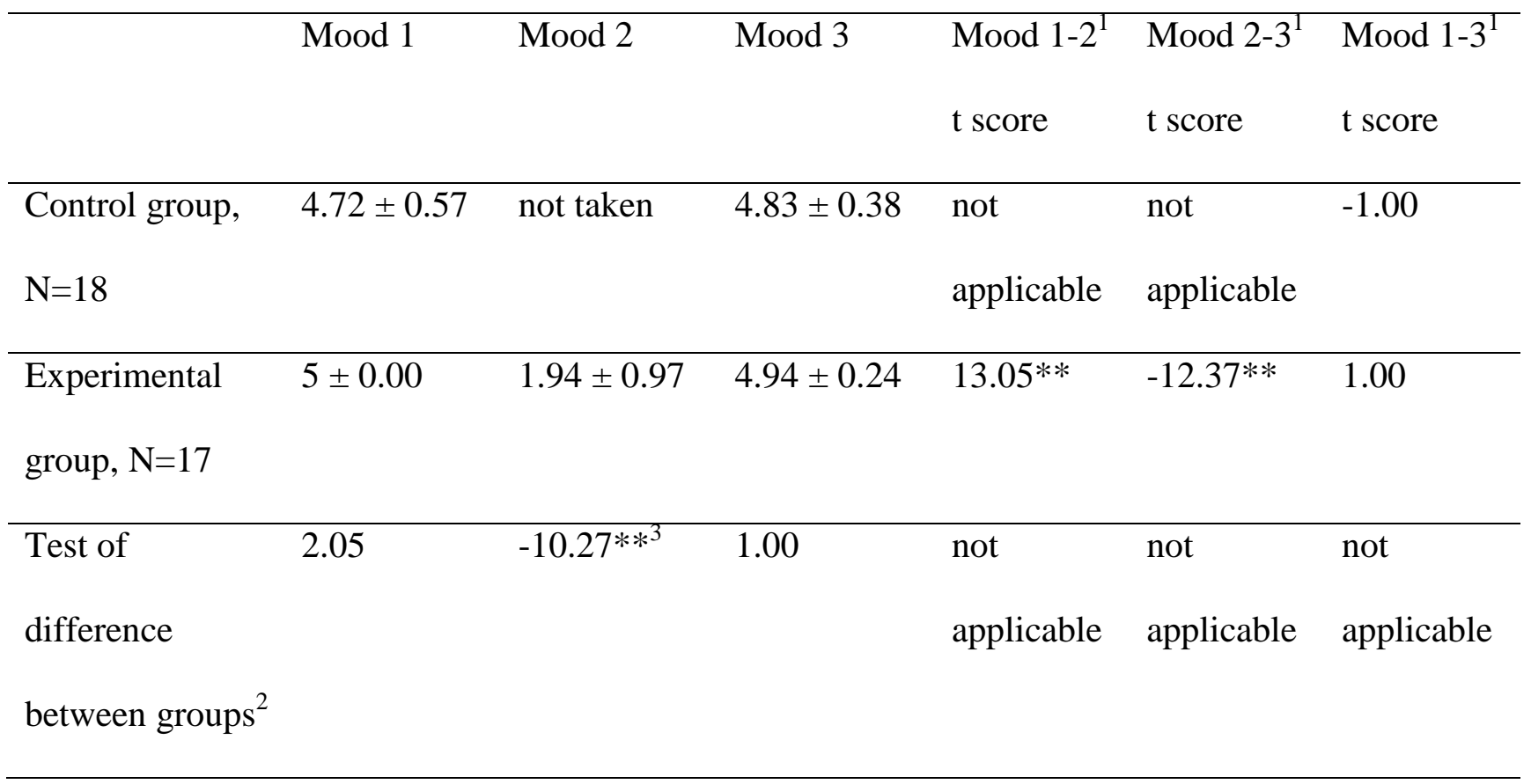

Mood 1 = baseline mood; Mood 2 = mood after emotion induction (not taken for control children); Mood $3=\operatorname{mood}$ after completing procedure. ${ }^{1}$ Paired sample t- test used to compare within a group over time; ${ }^{2}$ Independent sample t-tests used to compare the 2 groups. ** $\mathrm{p}<0.001$; ${ }^{3}$ T-test comparing control group children's baseline mood to experimental group children's mood after the emotion induction. 
The development of emotional eating

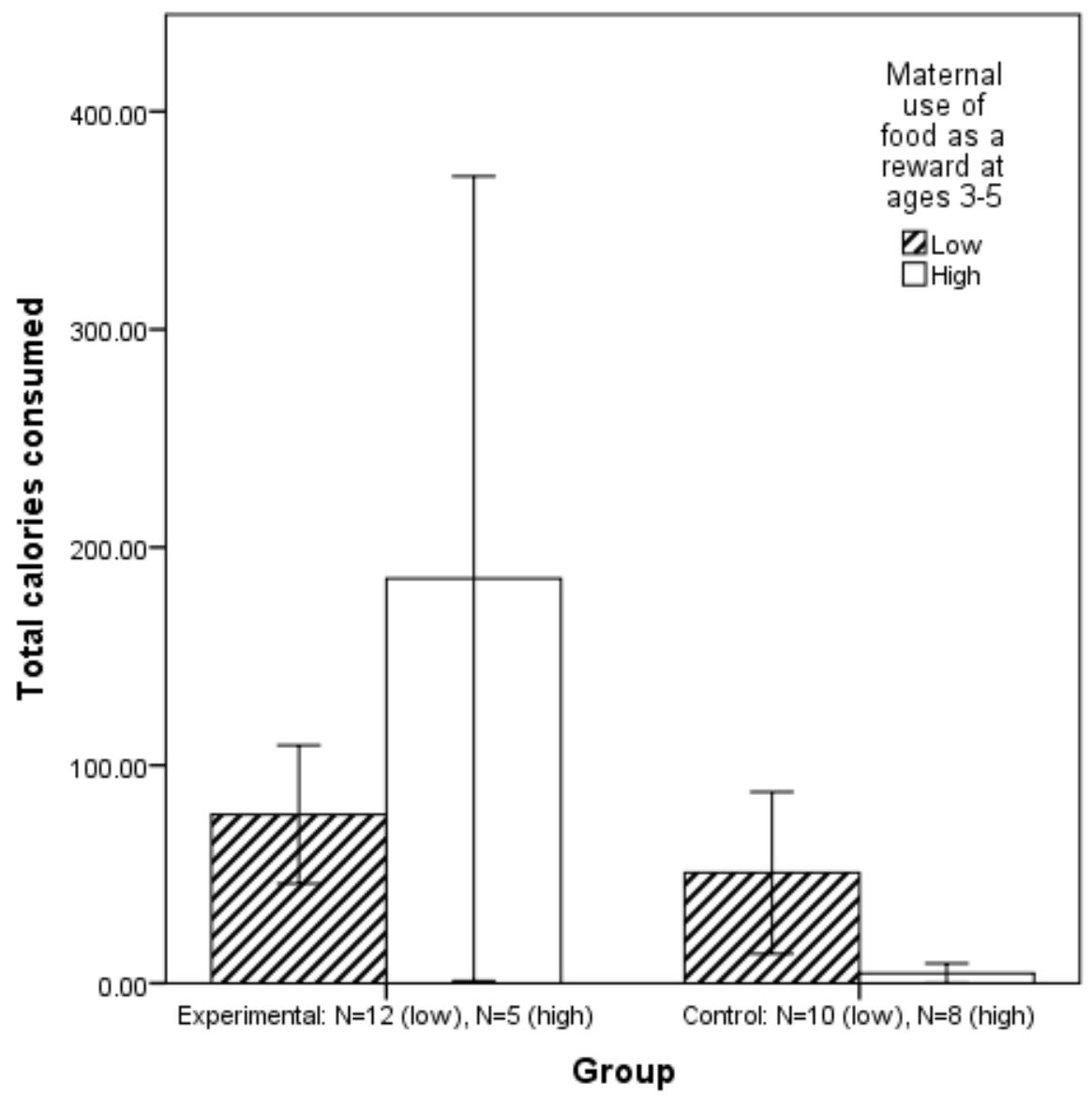

$F(1,29)=6.01, p<0.05 . \quad$ Error Bars: $+/-2$ SE

Figure 1: Intake of calories at 5-7 years under conditions of stress or control for children exposed to high or low use of food as a reward. ANCOVA used to analyse data. 
The development of emotional eating

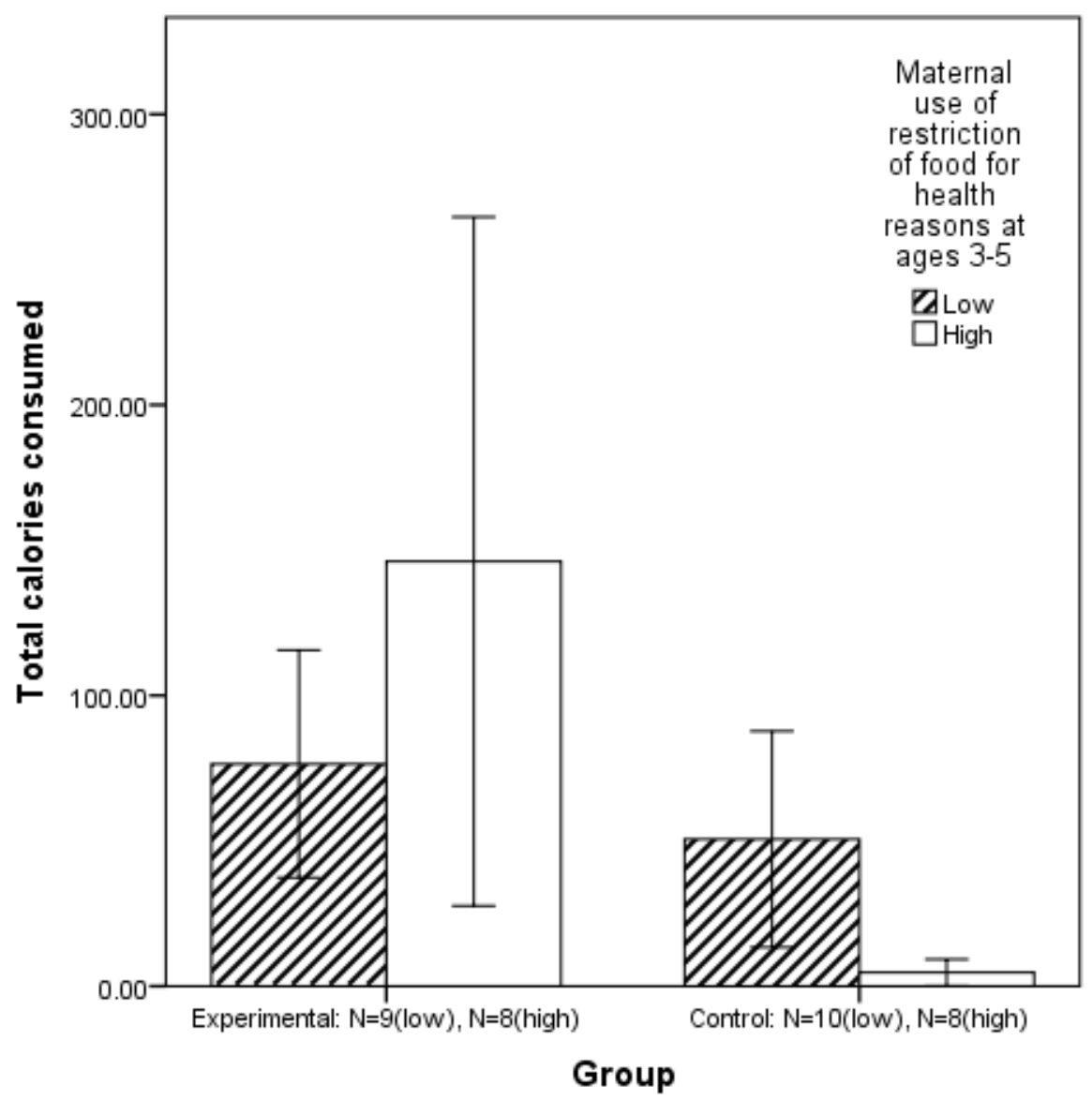

$F(1,29)=5.48, p<0.05$.

Error Bars: +/- 2 SE

Figure 2: Intake of calories at 5-7 years under conditions of stress or control for children exposed to high or low restriction of food for health reasons. ANCOVA used to analyse data. 